\title{
Spider assemblages in floodplain forests along an urbanization gradient
}

\author{
B. Tajthi1 ${ }^{1}$ R. Horváth², Sz. Mizser¹, D. D. Nagy¹ and B. Tóthmérész ${ }^{1,2,3}$ \\ ${ }^{1}$ MTA-DE Biodiversity and Ecosystem Services Research Group, Debrecen, Egyetem square 1, H-4032 Hungary \\ ${ }^{2}$ University of Debrecen, Department of Ecology, Debrecen, Egyetem square 1, H-4032 Hungary \\ ${ }^{3}$ Corresponding author. E-mail: tothmerb@gmail.com
}

Keywords: Diversity, Floodplain forest, GlobeNet, Human disturbance, Litter sifting.

\begin{abstract}
Urban areas have been growing radically worldwide, causing considerable changes in biodiversity of natural habitats. In floodplain forests, we studied the effects of urbanization on ground-dwelling spider assemblages along a rural-suburban-urban gradient in Hungary. We tested three traditional hypotheses (intermediate disturbance hypothesis, habitat specialist hypothesis and hygrophilous species hypothesis) and two novel expectations (shade-preferring species hypothesis, and disturbance sensitive species hypothesis) on spiders. We found that the total number of species was higher in the suburban habitat than in rural and urban ones, supporting the intermediate disturbance hypothesis. We found a decrease in the species richness of forest specialist and shade-preferring species along the urbanization gradient. We found that the number of hygrophilous and disturbance sensitive species was the lowest in the urban habitat. The spider assemblages of the rural and suburban habitats were clearly separated from the assemblages of urban habitats. Based on our findings we emphasize that low and moderate intensity of forest management contributes to the preservation of the local species richness in floodplain forests.
\end{abstract}

Nomenclature: World Spider Catalog (2018).

Abbreviations: GLM - Generalised Linear Model; MDS - MultiDimensional Scaling.

\section{Introduction}

Increase in the area of urbanized habitats causes loss of biodiversity and natural habitats at both local and global scales all across the world (McDonald et al. 2008). Urbanization reduces the species richness, mainly in the densely inhabited and built-up city centres and in the intensively managed areas; however, effects of urbanization differ between each taxonomic group (McKinney 2008, Niemelä and Kotze 2009). Several earlier studies pointed out that species richness is equal or sometimes higher in urbanized habitats than in the surrounding natural habitats (Magura et al. 2010b, Sattler et al. 2011). Nevertheless, original assemblages suffer from the habitat alteration caused by urbanization due to the appearance of non-native and cosmopolitan species (Olden and Poff 2003). These species may increase the local biodiversity, but on a regional scale diversity shows a decrease due to the extinction of endemic and endangered species (Czech et al. 2000, McKinney 2006).

With over one million identified species, arthropods are the most diversified invertebrate group in the world (Adler and Foottit 2009). Global environmental changes cause a biodiversity loss in altered habitats; therefore, several indigenous arthropod species may become seriously threatened (Stork 2010). It is important to stress that the disappearance of these species from their natural habitats influences adversely the function of ecosystems (Cardinale et al. 2012). Investigation of arthropod assemblages and their interactions can provide a good opportunity to get an insight into urbanization pro- cesses which may influence ecosystem structure and function (Gardnier et al. 2013). Many arthropod groups respond quickly to environmental changes; thus, they are suitable indicators of the biodiversity change (McIntyre 2000, McIntyre et al. 2001).

In this paper, we studied ground-dwelling spiders (Araneae), because they are useful indicator organisms to appreciate anthropogenic activities such as urbanization (Miyashita et al. 1998), forest management (Debnár et al. 2016) and air pollution (Horváth et al. 2001). As an abundant and species-rich arthropod taxon, spiders are important in the regulation of insect populations contributing to ecosystem services, since they are essential predators of pest (Nyffeler 2000). Spiders are especially useful to test the influence of disturbance on biodiversity (Horváth et al. 2009, 2012, 2013), as they respond sensitively and quickly to environmental changes due to their short life-cycles (Miyashita et al. 1998, Foelix 2011).

Floodplain forests provide excellent opportunities for researchers to investigate the effect of urbanization in strongly changing environments (Renofalt et al. 2005, Lambeets et al. 2008). Thus, the aim of this research was to study the impact of urbanization on the ground-dwelling spider assemblages along a rural-suburban-urban gradient in floodplain forests. There are numerous published hypotheses to explain the effects of human disturbances on terrestrial biotic communities (Niemelä et al. 2000). We tested three widely used and two novel hypotheses regarding the reaction of spiders to urbanization: (1) intermediate disturbance hypothesis claims that 
diversity should be the highest in areas under intermediate levels of disturbance (Connell 1978). The increasing level of disturbance is unfavourable for the forest specialist species which are adapted to the environmental conditions of forests. Thus, (2) the habitat specialist hypothesis predicts that the species richness of forest specialists decrease from the rural habitat towards the urban one (Magura et al. 2004).

Persistence and/or survival of spiders with various ecological traits also depend on the light and humidity conditions of the environment and also depend on their disturbance sensitivity (Buchar and Růžička 2002). Therefore, we studied the spiders based on three ecological traits (humidity preference, shade preference and disturbance sensitivity): the urban forest fragments become drier compared to unmanaged rural sites due to the intensive urban forest management; thus, (3) the dominance of hygrophilous species should decrease from the rural habitat to the urban one (hygrophilous species hypothesis, Magura et al. 2013). The urban forest fragments are more open and lighter than the unmanaged rural sites; thus, (4) we expected that the number of shade-preferring species should decrease towards the urban habitat (shade-preferring species hypothesis). Several spider species are sensitive to the anthropogenic disturbances; therefore, (5) we expected that the species richness of disturbance sensitive species decreases along the rural-suburban-urban gradient (disturbance sensitive species hypothesis).

\section{Methods}

\section{Study area and sampling design}

The study areas were located within and around Szeged city, in the South of the Great Hungarian Plain (Hungary) in the floodplain of river Tisza. Our sampling design was based on the international GlobeNet protocol. This project explores the responses of arthropods to urbanisation, using unified methods (Niemelä et al. 2002). According to the GlobeNet protocol, twelve sampling sites were selected along an urbanization gradient (four of each habitat type: rural, suburban, and urban forests). To identify the location of sampling sites a map (Fig. 1) was provided. All sampling sites were larger than $2500 \mathrm{~m}^{2}$. The distance between the studied areas (rural, suburban, and urban) was at least $1 \mathrm{~km}$. The distance between the sites was at least $100 \mathrm{~m}$. All selected sites were in floodplain forests. The last flood interruption in the studied area was in 2013. The most frequent species in the tree layer of the forest were silver poplar (Populus alba), white willow (Salix alba) and white elm (Ulmus laevis) mixed with European ash (Fraxinus excelsior) and London plane tree (Platanus $\times$ acerifolia). The intensity of forestry management operations was low in the rural habitat and there were no buildings there. In the suburban habitat, there were walking and hiking paths, and it was moderately visited by hikers and dog walkers. The understory was not thinned, the fallen trees and branches were regularly removed. The urban sites were located nearby a frequently visited riverbank and a canoe-camping. In the urban forested habitat fallen trees and branches were frequently removed, the shrub layer was strongly thinned, resulting in a park character. The lawn in the urban fragments was often mowed, and the mowed phytomass was removed.

We used a metal quadrat $(25 \mathrm{~cm} \times 25 \mathrm{~cm} \times 5 \mathrm{~cm})$ to collect spider species. During the sampling we collected the litter, soil and woody debris from the upper $5 \mathrm{~cm}$ of litter and ground layers, and sifted through a wire-grid $(30 \mathrm{~cm}$ in diameter with $1 \mathrm{~cm}$ in diameter size grids), which was sewn to a cloth sleeve (Nagy et al. 2016). There were five random litter samples in each sampling site, and the distance between the samples was at least $20 \mathrm{~m}$. Altogether, there were 60 litter samples ( 3 habitat types $\times 4$ sites $\times 5$ litter samples) in every sampling date. We collected spiders fortnightly from the end of April to the end of October, in 2014. For statistical evaluation, each sample was pooled for the whole sampling period, resulting in 60 data sets ( 12 sites $\times 5$ samples). To avoid edge
Figure 1. Map of the study area. The study area is in and around Szeged City $\left(46^{\circ} 15^{\prime} \mathrm{N}, 20^{\circ} 10^{\prime} \mathrm{E}\right)$. The dotted areas indicate the forested areas. Circles indicate the locations of the twelve sampling sites. Letters indicate the habitat types: R - rural, SU - suburban, U - urban.

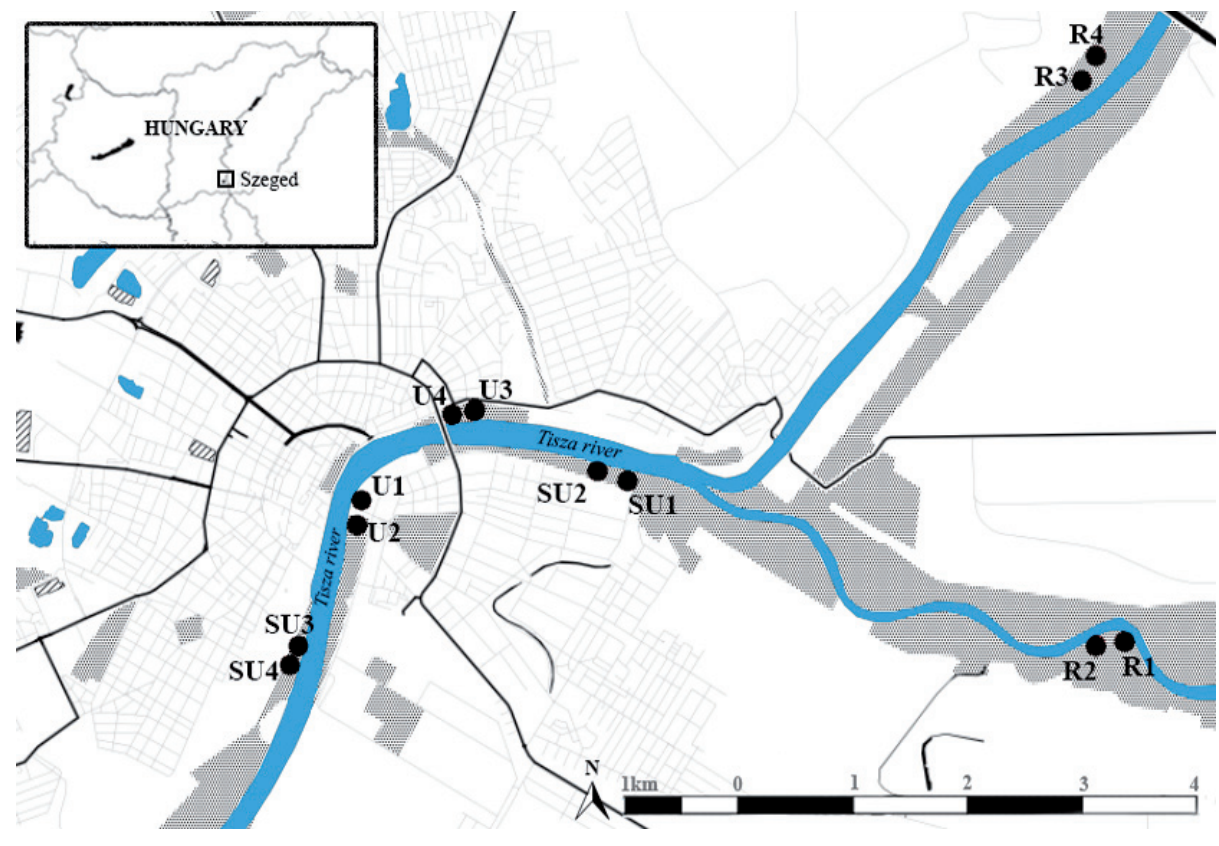


Table 1. Mean values ( \pm SE) of the measured environmental variables in the three studied habitat types.

\begin{tabular}{lccl}
\hline $\begin{array}{l}\text { Environmental } \\
\text { variables }\end{array}$ & Rural & Suburban & Urban \\
\hline Relative humidity (\%) & $76.3 \pm 0.86$ & $70.4 \pm 0.97$ & $58.3 \pm 1.05$ \\
Cover of leaf litter (\%) & $24.3 \pm 2.25$ & $22.6 \pm 2.42$ & $15.2 \pm 1.75$ \\
Cover of decaying & $16.1 \pm 1.13$ & $15.3 \pm 1.22$ & $5.2 \pm 0.23$ \\
wood material (\%) & $24.1 \pm 2.83$ & $25.3 \pm 3.09$ & $37.2 \pm 1.13$ \\
Cover of herbs (\%) & $47.6 \pm 1.24$ & $53.4 \pm 1.13$ & $5.3 \pm 1.82$ \\
Cover of shrubs (\%) & $94.2 \pm 1.12$ & $82.4 \pm 1.52$ & $64.7 \pm 2.64$ \\
Canopy cover (\%) & &
\end{tabular}

effect, each sampling points were at least $50 \mathrm{~m}$ from the nearest forest edge (Horváth et al. 2002). We stored the samples in plastic bags and sorted within 48 hours. We preserved the collected species in $70 \%$ ethanol. We identified spiders to species level using standard keys (Nentwig et al. 2018). We measured six environmental variables at each sampling point in the studied year, which can affect spiders (Table 1).

\section{Data analysis}

The overall species richness is not suitable indicator of disturbance caused by humans; therefore, species with different ecological traits should be analyzed separately as ignoring these traits masks the real effects of urbanization (Magura et al. 2010a,b). Thus, we categorized the collected species according to their habitat affinity (forest specialists, generalist, and open-habitat species), humidity preference (hygrophilous, eurytopic and xerophilous) and shade preference (shadepreferring species, eurytopic and light-preferring) based on the literature (Buchar and Růžička 2002) and our earlier field experience (Table 2). For the disturbance sensitive species hypothesis, we used a simplified categorization of Buchar and Růžička (2002). They distinguished four types of habitats based on the degree of disturbance: climax (i.e., undisturbed natural communities), semi-natural, disturbed, and artificial habitats (buildings). Based on their work we categorized the species as disturbance sensitive (species appear only in climax and/or semi-natural habitats) or non-sensitive species to disturbance or disturbance-tolerant species (species appear in disturbed and/or artificial habitats) (Table 2).

We used Generalised Linear Models (GLMs) with Poisson link-function to test differences in the overall spider species richness (number of species per sample), the species richness of the spider with various habitat affinities, humidity preference and disturbance sensitivity between the ruralsuburban-urban areas and the twelve sites. We used a nested design; four sites were nested within a given sampling area. When there was a significant difference between the means we used a Fisher LSD test for multiple comparisons among means (StatSoft Inc. 2010).

We analysed the composition of spider assemblages at site level along the urbanization gradient by cluster analysis and multidimensional scaling (MDS) based on the abundance of spiders using Hellinger distance and Ward fusion method (Legendre and Legendre 2012). We compared the diversity of the spider assemblages of the rural, suburban and urban habitats using Rényi diversity index family (Tóthmérész 1998 2009). It is defined as:

$$
H R(a)=\frac{1}{1-a}\left(\log \sum_{i=1}^{s} p_{i}^{a}\right)
$$

where $p_{i}$ is the relative frequency of the $i$-th species, $S$ the total number of species and $\alpha$ is a scale parameter $(\alpha \geq 0, \alpha \neq 1)$. It is called "diversity index families" because it includes four classical diversity statistics as special value (Patil and Taillie 1982, Tóthmérész 1995): (i) at $\alpha=0$, the value of the Rényi diversity is equal to the logarithm of the number of species of the community; (ii) at $\alpha \rightarrow 1$, it is identical to the Shannon diversity; (iii) at $\alpha=2$ it is related to the Simpson diversity, and (iv) at $\alpha \rightarrow+\infty$, the value of the Rényi diversity is the inverse of the Berger-Parker dominance index.

At small values of the scale parameter of Rényi diversity is sensitive to the rare species; when the scale parameter increases, the diversity value is increasingly influenced by the common species. Finally, at large scale parameter values, only the abundance of the most common species determines the diversity, similarly to the Berger-Parker diversity (Tóthmérész 1995). This approach produces a diversity profile, allowing a synthetic assessment of diversity relations among assemblages (Tóthmérész 1998). When two diversity profiles do not intersect each other, the assemblage whose diversity profile runs above the other one is unequivocally more diverse. When the profiles cross, one assemblage is more diverse for the rare species, while the other one is more diverse for the common species. For these calculations we used the $\mathrm{R}$ version 3.4.3 and the vegan package (R Core Team 2017, Oksanen et al. 2017, respectively).

\section{Results}

We collected 413 individuals belonging to 41 spider species (Table 2 ). The overall species richness was significantly higher in the suburban sites than the rural and urban ones $\left(\chi^{2}\right.$ $=13.8617 ; \mathrm{df}=2,9 ; \mathrm{p}<0.011 ;$ Fig. $2 \mathrm{~A})$. In case of forest specialist and shade-preferring spiders the species number was higher in the rural habitat than in the urban one (forest specialist spiders: $\chi^{2}=11.4471 ; \mathrm{df}=2,9 ; \mathrm{p}<0.003$; Fig. $2 \mathrm{~B}$; shade-preferring spiders: $\chi^{2}=13.2025$; $\mathrm{df}=2,9 ; \mathrm{p}<0.001$; Fig. 2C). The species richness of hygrophilous spiders was significantly higher in the rural and suburban sites than in the urban one $\left(\chi^{2}=39.1095 ; \mathrm{df}=2,9 ; \mathrm{p}<0.001\right.$; Fig. $\left.2 \mathrm{D}\right)$. The diversity of disturbance sensitive species was significantly higher in the rural and suburban sites than in the urban ones $\left(\chi^{2}=29.8304 ; \mathrm{df}=2,9 ; \mathrm{p}<0.001 ;\right.$ Fig. 2E $)$.

Cluster analysis revealed that the spider assemblages in the rural and suburban areas were separated compositionally from that of the urban ones (Fig. 3A), and the four urban sites formed a separate group. This pattern was corroborated by the MDS ordination (Fig. 3B). Diversity profiles of the Rényi diversity showed that the suburban habitat supported the most 
Table 2. The number of individuals of the collected spider species and their ecological traits along the urban-rural gradient in the studied floodplain forests. Notations: "shade" denotes shade-preferring species, "light" denotes light-preferring species.

\begin{tabular}{|c|c|c|c|c|c|c|c|}
\hline Species & $\begin{array}{c}\text { Habitat } \\
\text { preference }\end{array}$ & $\begin{array}{l}\text { Humidity } \\
\text { preference }\end{array}$ & $\begin{array}{c}\text { Light } \\
\text { preference }\end{array}$ & $\begin{array}{c}\text { Disturbance } \\
\text { sensitivity }\end{array}$ & Rural & Suburban & Urban \\
\hline Agyneta rurestris & generalist & eurytopic & eurytopic & non-sensitive & 0 & 1 & 5 \\
\hline Centromerus sylvaticus & generalist & hygrophilous & eurytopic & non- sensitive & 0 & 3 & 0 \\
\hline Ceratinella brevipes & forest & xerophilous & shade & sensitive & 3 & 0 & 0 \\
\hline Crustulia guttata & generalist & xerophilous & eurytopic & sensitive & 1 & 0 & 0 \\
\hline Cyclosa conica & forest & eurytopic & shade & sensitive & 1 & 1 & 0 \\
\hline Dictyna uncinata & generalist & eurytopic & shade & non-sensitive & 1 & 1 & 2 \\
\hline Diplocephalus picinus & forest & hygrophilous & shade & sensitive & 22 & 15 & 11 \\
\hline Liocranoeca striata & generalist & hygrophilous & eurytopic & sensitive & 19 & 34 & 0 \\
\hline Metopobactrus ascitus & generalist & eurytopic & eurytopic & sensitive & 0 & 0 & 1 \\
\hline Neon reticulatus & forest & hygrophilous & shade & sensitive & 0 & 1 & 0 \\
\hline Ozyptila praticola & forest & hygrophilous & shade & sensitive & 64 & 56 & 26 \\
\hline Pachygnatha listeri & forest & hygrophilous & eurytopic & sensitive & 2 & 0 & 0 \\
\hline Pardosa sp. & $\mathrm{N} / \mathrm{A}$ & $\mathrm{N} / \mathrm{A}$ & N/A & N/A & 9 & 36 & 5 \\
\hline Philodromidae sp. & N/A & N/A & N/A & N/A & 0 & 0 & 1 \\
\hline Phrurolithus festivus & generalist & eurytopic & eurytopic & sensitive & 2 & 17 & 4 \\
\hline Tapinocyba insecta & forest & hygrophilous & shade & sensitive & 2 & 0 & 0 \\
\hline Tapinocyba pallens & forest & hygrophilous & shade & sensitive & 0 & 1 & 0 \\
\hline Tenuiphantes flavipes & forest & eurytopic & eurytopic & sensitive & 2 & 4 & 0 \\
\hline Tenuiphantes tenuis & generalist & eurytopic & eurytopic & non-sensitive & 0 & 0 & 2 \\
\hline Tenuiphantes zimmermanni & forest & hygrophilous & shade & sensitive & 0 & 1 & 0 \\
\hline Tetragnathasp. & N/A & N/A & N/A & N/A & 1 & 1 & 0 \\
\hline Tmarus piger & generalist & eurytopic & shade & sensitive & 1 & 0 & 0 \\
\hline Trachyzelotes pedestris & generalist & eurytopic & light & sensitive & 0 & 0 & 1 \\
\hline Trochosa ruricola & open habitat & hygrophilous & light & non-sensitive & 0 & 1 & 0 \\
\hline Walckenaria nudipalpis & generalist & hygrophilous & eurytopic & sensitive & 2 & 0 & 0 \\
\hline Xysticus sp. & N/A & N/A & $\mathrm{N} / \mathrm{A}$ & N/A & 0 & 2 & 7 \\
\hline Zelotes aeneus & open habitat & xerophilous & light & non-sensitive & 0 & 0 & 1 \\
\hline Zelotes exiguus & generalist & xerophilous & light & sensitive & 0 & 1 & 0 \\
\hline Total & & & & & 148 & 192 & 79 \\
\hline
\end{tabular}

diverse spider assemblages, while the urban assemblages were the least diverse (Fig. 4).

\section{Discussion}

We studied the effects of urbanization on ground-dwelling spider assemblages of floodplain forests along a rural-subur- ban-urban gradient in Szeged city (Hungary). The number of collected spider species in our study (41 species) was about $5 \%$ of the Hungarian spider fauna (Samu and Szinetár 1999).

Our results supported the intermediate disturbance hypothesis. There is only one investigation reporting the validity of this prediction for spiders, reported from Paris (France) (Vergnes et al. 2014), while other studies reported that spi- 

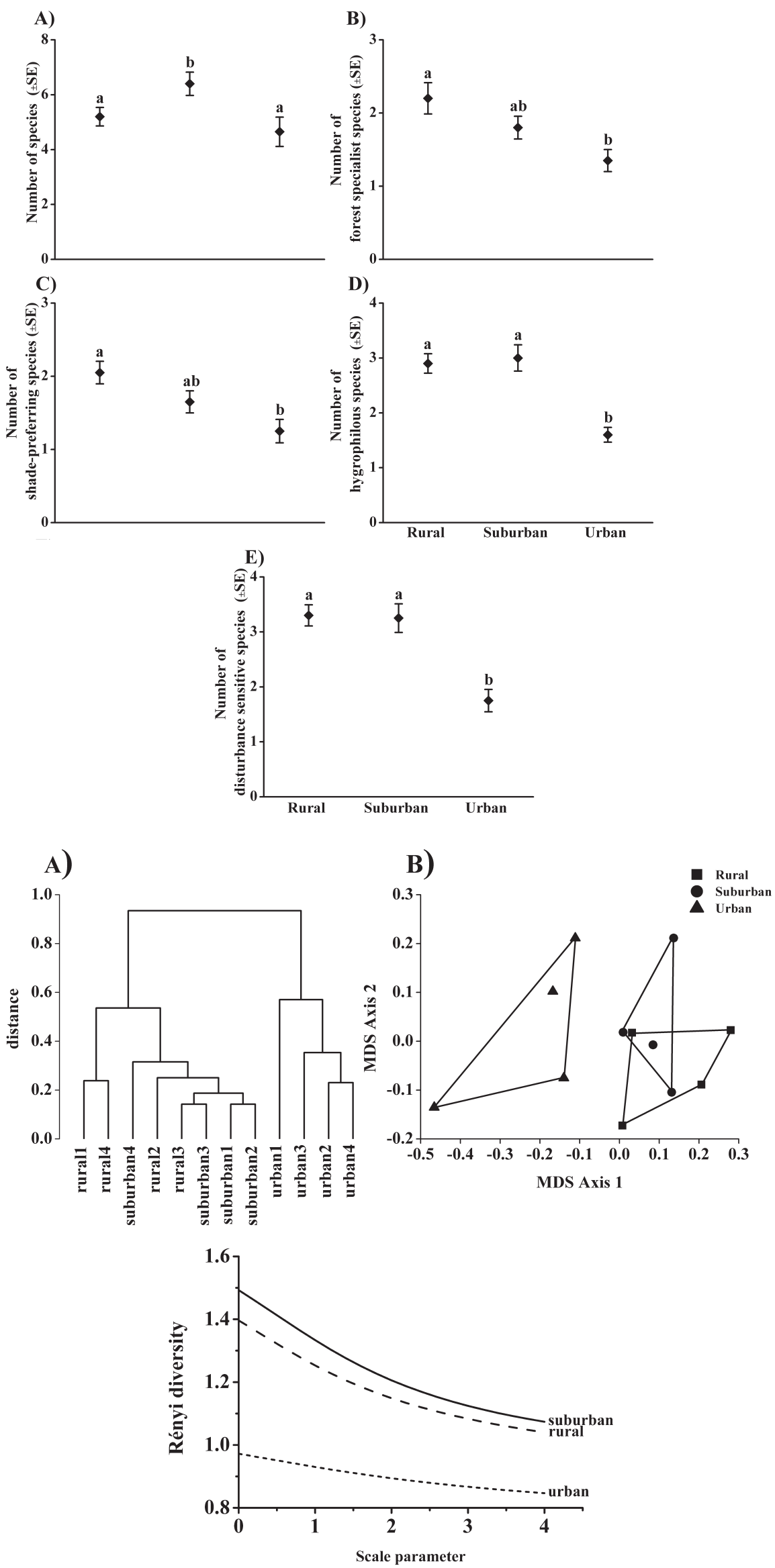

Figure 2. Mean value of the total number $( \pm \mathrm{SE})$ of spider species (A), the number of forest specialist spider species (B), the number of shade-preferring spider species (C), the number of hygrophilous spider species (D), and the disturbance sensitive spider species (E) per trap along the studied rural-suburban-urban gradient in floodplain forests in Hungary. Means that share the same letter are not significantly different from one another $(\mathrm{p}<0.05)$ by Fisher LSD test.

Figure 3. Hierarchical cluster analysis using Hellinger distance and Ward fusion method (A), and multidimensional scaling (MDS) based on the Hellinger distance (B) of species compositions of spider assemblages in floodplain forests along a rural-suburban-urban gradient.

Figure 4. Diversity profiles of the spider assemblages along the rural-suburban-urban gradient in floodplain forests in Hungary based on the one-parametric scalable Rényi diversity index family. 
der species richness was the highest in the urban habitat in Debrecen (Hungary) (Magura et al. 2010b, Horváth et al. 2012), or there was no significant difference along the urbanization gradient (Helsinki-Espoo area of southern Finland, Alaruikka et al. 2002). This hypothesis was rarely verified for other arthropod taxa; most of studies reported a decrease in arthropod species richness along rural-suburban-urban gradient (Niemelä et al. 2002, Ishitani et al. 2003). However, some previous studies also reported the intermediate disturbance hypothesis for ground beetles and rove beetles (Tóthmérész et al. 2011, Vergnes et al. 2014). Higher habitat heterogeneity may support higher species richness in and around cities than in stable natural forest ecosystems (Smith et al. 2006). In our study the higher habitat heterogeneity of the suburban habitat had a positive effect on spider diversity. In the suburban habitat, both strongly closed and moderately closed canopy patches appeared due to the moderate level of forestry management. This heterogeneity might support a higher diversity of spiders in this area. The results of Rényi diversity also supported the intermediate disturbance hypothesis as diversity of both the rare and the common species was the highest for the suburban area. The urban assemblage was the least diverse both for the rare and the common species.

Decline of species richness of forest specialist spiders was consistent with the previous findings showing change in composition and in species richness of forest specialist assemblages along the urbanization gradient (carabids: Magura et al. 2008, 2010b; Tóthmérész et al. 2011, spiders: Horváth et al. 2012; various taxa: McKinney 2006, 2008,). Forest specialist spider species are usually less adapted to urban habitats characterized by high temperature, high aridity and higher level of light than generalist and open-habitat species (Magura et al. 2010b, Horváth et al. 2012). Some of these species can also survive in moderately disturbed suburban sites. Moreover, in a previous study Horváth et al. (2012) found that the species richness of forest specialist spiders was the highest in the suburban habitat, since the degree of canopy closure and the humidity level were the highest in this habitat. Ryndock et al. (2012) also stressed the influence of canopy closure, because they found a significant negative relationship between the species richness of forest specialist spiders and the canopy openness in the differently treated oak woodlands. Usually forest specialist species favour shaded and humid forests and they are sensitive to the human disturbances. In our case the degree of canopy closure and the level of disturbance were similar between rural and suburban sites; therefore, both habitat types provided favourable conditions for the forest specialist species. In our urban habitat pathways fragmented the large, continuous green areas into smaller patches resulting lower canopy closure and air humidity, and these processes may cause the loss of diversity of forest specialist spiders in urban sites.

Our findings supported the assumption about the decrease of hygrophilous species along the urbanization gradient. The undisturbed rural sites and the moderately disturbed suburban sites were more closed by tree canopy than the urban ones; thus, the relative humidity was higher in these habitats. This contributed to the higher species richness of hygrophilous spiders in the rural and suburban sites compared to the urban ones. Our findings also corroborated the expectations of the shade-preferring species hypothesis. The rural forest was the most closed, but the degree of canopy closure was also high in the suburban habitat. These were shadier than the urban sites. Thus, in the urban forest patches shade-preferring species did not find favourable microhabitats and they cannot colonize these sites.

We found that species richness of the disturbance sensitive species decreased with the increasing level of urbanization in cohrence with the disturbance sensitive species hypothesis. Most spider species are moderately or strongly sensitive to both natural and human disturbances; thus, their abundance decreases by increasing level of disturbance or they become extinct from the disturbed habitats (Miyashita et al. 1998, Horváth et al. 2001, 2009). There was just a minor management activity in the suburban area, causing only slight disturbance. This was corroborated with our findings: there was just a slight decrease (not significant) in the number of disturbance sensitive species compared to the rural area. The urban area was characterized by a high intensity of management, which resulted in a park character of the area with strongly modified micro-habitats compared to the native floodplain forests. The high level of disturbance caused by these changes resulted in a strong (highly significant) decrease in the number of disturbance sensitive spider species. Thus, we found that the number of disturbance sensitive spider species was an especially useful indicator of the level of urbanization.

The hierarchical cluster analysis and MDS ordination also showed a clear separation of urban sites from the other sites, which indicated that due to urbanization the spider assemblages of these sites were remarkably different from the that of the rural and suburban ones. Similarity between the assemblages of rural and suburban sites was high. Forest specialist species preferred mainly the undisturbed rural and moderately disturbed suburban sites, while generalist and open-habitat species were abundant in the urban habitat. In urban sites, there were patches with high and moderate canopy closure, and also with open patches, because of pavements, pathways and forestry management, which resulted in a diverse horizontal and vertical structure of the forest. Despite the structural heterogeneity, urban habitat did not provide suitable environmental conditions for the forest specialist species. The decrease of species richness of forest specialist spiders in the urban sites also showed the disturbance sensitivity of these species.

\section{Conclusion}

Floodplain forests are a highly fluctuating, stochastic environment. They are especially sensitive to the effects of urbanization. These changes influenced the species richness and species composition of spider assemblages. Remarkably, the overall species richness was the highest in the suburban habitat. Due to the moderate level of management, there were both closed and moderately closed patches in these habitats; therefore, forest specialist, hygrophilous species and shade- 
preferring species can survive in these habitats. Our results showed that the species richness of specialist spiders which were adapted to the characteristics of rural floodplain forests decreased significantly with increasing level of urbanization. Forest specialist species need special microsites with unique environmental conditions in the strongly closed canopy patches. Intensive management in urban sites eliminates the special microsites. Our findings suggest that it is important to support and/or increase habitat heterogeneity and the quality of the microsites in closed and open patches to maintain the diversity of spiders.

Acknowledgements: We are thankful to Zs. Debnár, T. Magura, Cs. Eötvös and Sz. Radócz for their help during the field work. The presented research was supported by OTKA K 116639, HK 126477 projects, and Ministry of Human Resources, in the program of National Talent Program NTPNFTÖ-16 - scholarships to provide individual development.

\section{References}

Adler, P.H. and R.G. Foottit. 2009. Introduction. In: Foottit, R.G. and P.H. Adler (eds). Insect Biodiversity: Science and Society. WileyBlackwell, Chichester, pp. 1-6.

Alaruikka, D.M., D.J. Kotze, K. Matveinen and J. Niemelä. 2002. Carabid beetle and spider assemblages along a forested urbanrural gradient in Southern Finland. J. Insect Conserv. 6:195-206.

Buchar, J. and V. Růžička. 2002. Catalogue of Spiders of the Czech Republic, 1st ed. Peres Publishers, Praha.

Cardinale, B.J, J.E. Duffy, A. Gonzalez, D.U. Hooper, C. Perrings, P. Venail, A. Narwani, G.M. Mace, D. Tilman and D.A. Wardle. 2012. Biodiversity loss and its impact on humanity. Nature 486:59-67.

Connell, J.H. 1978. Diversity in tropical rain forests and coral reefs. Science 199:1302-1310.

Czech, B., P.R. Krausman and P.K. Devers. 2000. Economic associations among causes of species endangerment in the United States. BioScience 50:593-601.

Debnár, Z., T. Magura, R. Horváth, D.D. Nagy, S. Mizser, A. Demkó, B. Tajthi and B. Tóthmérész. 2016. Group selection harvesting supports diversity of forest specialist epigaeic arthropods (Coleoptera: Carabidae; Arachnida: Araneae; Isopoda: Oniscidae). Period. Biol. 118:311-314.

Foelix, R.F. 2011. The Biology of Spiders. Oxford University Press, Oxford.

Gardnier, M.M., C.E. Burkman and S.P. Prajzner. 2013. The value of urban vacant land to support arthropod biodiversity and ecosystem services. Environ. Entomol. 42:1123-1136.

Horváth, R., Z. Elek and G.L. Lövei. 2014. Compositional changes in spider (Araneae) assemblages along an urbanization gradient near a Danish town. B. Insectol. 67:255-264.

Horváth, R., T. Magura and C. Szinetár. 2001. Effects of immission load on spiders living on black pine. Biodivers. Conserv. 10:1531-1542.

Horváth, R., T. Magura, G. Péter and B. Tóthmérész. 2002. Edge effect on weevils and spiders. Web Ecol. 3:43-47.

Horváth, R., T. Magura, C. Szinetár and B. Tóthmérész. 2009. Spiders are not less diverse in small and isolated grasslands, but less diverse in overgrazed grasslands; a field study (East Hungary, Nyírség). Agr. Ecosyst. Environ. 130:16-22.
Horváth, R., T. Magura and B. Tóthmérész. 2012. Ignoring ecological demands masks the real effect of urbanization: a case study of ground-dwelling spiders along a rural-urban gradient in a lowland forest in Hungary. Ecol. Res. 27:1069-1077.

Horváth, R., T. Magura, C. Szinetár, J. Eichardt and B. Tóthmérész. 2013. Large and least isolated fragments preserve habitat specialist spiders best in dry sandy grasslands in Hungary. Biodivers. Conserv. 22:2139-2150.

Ishitani, M., D.J. Kotze and J. Niemelä. 2003. Changes in carabid beetle assemblages across an urban-rural gradient in Japan. Ecography 26:481-489.

Lambeets, K., M.L. Vandegehuchte, J.P. Maelfait and D. Bonte. 2008. Understanding the impact of flooding on trait-displacements and shifts in assemblage structure of predatory arthropods on river banks. J. Anim. Ecol. 77:1162-1174.

Legendre, P. and L. Legendre. 2012. Numerical Ecology, 3rd ed. Elsevier Science, Amsterdam.

Magura, T., B. Tóthmérész and T. Molnár. 2004. Changes in carabid beetle assemblages along an urbanization gradient in the city of Debrecen, Hungary. Landsc. Ecol. 19:747-759.

Magura, T., B. Tóthmérész and T. Molnár. 2008. A species-level comparison of occurrence patterns in carabids along an urbanization gradient. Landsc. Urban Plan. 86:134-140.

Magura, T., G.L. Lövei and B. Tóthmérész. 2010a. Does urbanization decrease diversity in ground beetle (Carabidae) assemblages? Global Ecol. Biogeogr. 19:16-26.

Magura, T., R. Horváth and B. Tóthmérész. 2010b. Effects of urbanization on ground-dwelling spiders in forest patches, in Hungary. Landsc. Ecol. 25:621-629.

Magura, T., D. Nagy and B. Tóthmérész. 2013. Rove beetles respond heterogeneously to urbanization. J. Insect Conserv. 17:715-724.

McDonald, R.I., P. Kareiva and R.T. Forman. 2008. The implications of current and future urbanization for global protected areas and biodiversity conservation. Biol. Conserv. 141:1695-1703.

McIntyre, N.E. 2000. Ecology of urban arthropods: a review and a call to action. Ann. Entomol. Soc. Am. 93:825-835.

McIntyre, N.E., J. Rango, W.F. Fagan and S.H. Faeth. 2001. Ground arthropod community structure in a heterogeneous urban environment. Landsc. Urban Plan. 52:257-274.

McKinney, M.L. 2006. Urbanization as a major cause of biotic homogenization. Biol. Cons. 127:247-260.

McKinney, M.L. 2008. Effects of urbanization on species richness: A review of plants and animals. Urban Ecosyst. 11:161-176.

Miyashita, T., A. Shinkai and T. Chida. 1998. The effects of forest fragmentation on web spider communities in urban areas. Biol. Cons. 86:357-364.

Nagy, D.D., T. Magura, S. Mizser, Z. Debnár, R. Horváth and B. Tóthmérész. 2016. Recovery of surface-dwelling assemblages (Coleoptera: Carabidae, Staphylinidae) during clear-cut originated reforestation with native tree species. Period. Biol. 118:195203.

Nentwig, W., T. Blick, D. Gloor, A. Hänggi and C. Kropf. 2018. Spiders of Europe. http://www.araneae.unibe.ch. Accessed 15 January 2018.

Niemelä, J. and D.J. Kotze. 2009. Carabid beetle assemblages along urban to rural gradients: a review. Landsc. Urban Plan. 92:6571.

Niemelä, J., D.J. Kotze and A. Ashworth. 2000. The search for common anthropogenic impacts on biodiversity: a global network. $J$. Insect Conserv. 4:3-9. 
Niemelä, J., D.J. Kotze, S. Venn, L. Penev, I. Stoyanov, J. Spence and D. Hartley. 2002. Carabid beetle assemblages (Coleoptera, Carabidae) across urban-rural gradients: an international comparison. Landsc. Ecol. 17:387-401.

Nyffeler, M. 2000. Ecological impact of spider predation: a critical assessment of Bristowe's and Turnbull's estimates. Bull. Br. Arachnol. Soc. 11:367-373.

Oksanen, J., G.F. Blanchet, M. Friendly, R. Kindt, P. Legendre,. D. McGlinn, P.R. Minchin, R.B. O'Hara, G.L. Simpson, P. Solymos, M.H.H Stevens, E. Szoecs and H. Wagner. 2007. vegan: Community Ecology Package, R package version 2.4-4, https:// CRAN.R-project.org/package $=$ vegan

Olden, J.D. and N.L. Poff (2003) Toward a mechanistic understanding and prediction of biotic homogenization. Amer. Nat. $162: 442-460$

Patil, G.P. and C. Taillie. 1982. Diversity as a concept and its measurement. J. Am. Stat. Assoc. 77:548-567.

R Core Team. 2017. R: A language and environment for statistical computing. R Foundation for Statistical Computing, Vienna.

Renofalt, B.M., C. Nilsson and R. Jansson. 2005. Spatial and temporal patterns of species richness in a riparian landscape. $J$. Biogeogr. 32:2025-2037.

Ryndock, J.A., G.E. Stratton, J.S. Brewer and M.M. Holland. 2012. Differences in spider community composition among adjacent sites during initial stages of oak woodland restoration. Restor. Ecol. 20:24-32.

Samu, F. and C. Szinetár. 1999. Bibliographic check list of the Hungarian spider fauna. Bull. Br. Arachnol. Soc. 11:161-184.

Sattler, T., M.K. Obrist, P. Duelli and M. Moret. 2011. Urban arthropod communities: Added value or just a blend of surrounding biodiversity? Landsc. Urban Plan. 103:347-361.
Smith, R.M., K. Thompson, J.G. Hodgson, P.H. Warren and K.J. Gaston. 2006. Urban domestic gardens (IX): Composition and richness of the vascular plant flora, and implications for native biodiversity. Biol. Cons. 129:312-322.

Stork, N.E. 2010. Re-assessing current extinction rates. Biodivers. Conserv. 19:357-371.

Tóthmérész, B. 1995. Comparison of different methods for diversity ordering. J. Veg. Sci. 6:283-290.

Tóthmérész, B. 1998. On the characterization of scale-dependent diversity. Abstr. Bot. 22:149-156.

Tóthmérész, B., I. Máthé, E. Balázs and T. Magura. 2011. Responses of carabid beetles to urbanization in Transylvania (Romania). Landsc. Urban Plan. 101:330-337.

Vergnes, A., V. Pellissier, G. Lemperiere, C. Rollard and P. Clergeau. 2014. Urban densification causes the decline of ground-dwelling arthropods. Biodivers. Conserv. 23:1859-1877.

World Spider Catalog 2017. World Spider Catalog. Natural History Museum Bern. http://wsc.nmbe.ch. Accessed 15 January 2018.

Received November 9, 2017

Revised December 14, 2017

Accepted December 28, 2017

Open Access. This article is distributed under the terms of the Creative Commons Attribution 4.0 International License (https://creativecommons.org/licenses/by/4.0/), which permits unrestricted use, distribution, and reproduction in any medium, provided the original author and source are credited, you give a link to the Creative Commons License, and indicate if changes were made. 